\title{
A Critical Review on Mathematical Functions Employed for Heptane Plus Characterization in Gas Condensate Reservoirs: Lessons Learned and Future Development
}

\begin{abstract}
Steven Chandra ${ }^{1}$
${ }^{1}$ Well Stimulation Laboratory, Institut Teknologi Bandung

Abstract

Characterizing heptanes plus fraction in PVT analysis has been a complex problem since its first inception. In this publication, the author is reviewing available mathematical functions employed for this task, whilst pointing out advantages and weaknesses for each of them and proposing a new method that is capable of complex characterization.

This publication addresses a new method that is capable of accurately characterize heptane plus fraction especially in discontinued areas where errors could leap up to $40 \%$. The author modifies the natural logarithmic function to be used as an accommodation to discontinuities. The modified distribution provides better accuracy in modeling the discontinuities as a straight-line function, making them ideal for real gas condensate composition characterization. The new method is tested against several test data used by previous researchers and applied to 3 sets of field data. The results have shown that this new method is capable of lowering CPU requirement whilst making better accuracy for all test data.
\end{abstract}

Keywords: heptane plus, pseudo component, single carbon number

Corresponding Author: steven@tm.itb.ac.id

\section{INTRODUCTION}

The increasing demand for condensate products has reached a new level in this industrialized era. It is important for producers to maintain a steady supply of gas condensates to fulfill the world's need. However, producing from gas condensate reservoirs are not as simple as black oil or dry gas reservoirs. Its unique properties such as the retrograde condensation and loss of significant productivity at a certain dew point pressure make it impossible to apply general correlations based on simpler fluid.

Characterizing heptane plus fraction has been a latent problem in gas condensate field of expertise. The correlations developed mostly are fitted for certain data sets only, making it prone to errors in other data sets. Several authors have pointed different continuous distribution models, but it is important to note that discontinuities of the composition are a recurring phenomenon in gas condensate PVT study. Therefore, this issue should be resolved in a manner that allows easy and rapid calculation. Spivey and McCain (2013) highlighted the importance of heptane plus characterization, especially related to the high rise of the liquidrich gaseous reservoir, not only in Northern America but also all around the world. They also highlighted the importance of heavy hydrocarbon constituent's characterization in preliminary estimates before laboratory data is available, or when costly PVT testing are not available due to cost considerations and for comparison purposes, especially due to the fact that correlations related to gas condensate PVT are not as abundant as dry gases' or black oil related correlations (Imo-Jack \& Uche, 2012).

\section{LITERATURE STUDY}

Danesh (1998) and Ahmed (1989) pointed out the importance of characterizing compositions from a single carbon number ( $\mathrm{SCN}$ ) group for the sake of fluid characterization. In gas condensate reservoirs, proper fluid characterization should bring multiplier effects in the difficulty of production, field development, and surface treatment process design. However, it is a known field practice that extended composition of a gas condensate sample is not available experimentally due to technological constraints and economic 
consideration, therefore mathematical models popularly known as "splitting schemes" are often employed (Mayrhoo and Hosein, 2014).

There are several models available in the commercial equation of state simulation software that can be employed to extend the composition beyond measured heptane plus fraction such as Ahmed (1989), Danesh (1998), and Whitson and Brule (2000). However, there are only two models that are usually used which is the exponential model developed by Pedersen et al (1985) and three parameter Gamma distribution developed by Pearson (1895). The main assumption underlining these models is that the models can be applied to gas condensate systems as long as there is a continuous relationship between the pseudocomponent system and molecular weight. This assumption has been generated from observations in North Sea fields and expanded by Al-Meshari and McCain (2007) to several other data sets worldwide.

The continuous model, however, endures in gas condensate PVT characterization until Hosein and McCain (2009) published a new study that points out discontinuities in several test data worldwide, specifically in SCN8 and SCN 13. This phenomenon has been proven to limit the utilization of continuous models as the discontinuities are extracted from more reliable experimental measures.

In this publication, the author reviews the advantages and disadvantages of exponential distribution, threeparameter gamma distribution function, and the four-parameter coefficient model from Mayrhoo and Hosein (2014) and the author will propose a new model based on natural logarithmic function to properly accommodate discontinuous function.

\section{Previous Models Employed on Characterization of Heptane Plus Fraction in Gas Condensate Reservoir}

\section{Exponential Distribution Function}

The method was first suggested by Pedersen et al (1985) who observed that continuous exponential function can be model the relationship between mole percent expression as a function of molecular weight as

$$
\log z_{n}=A+B\left(M_{n}\right) \ldots(1)
$$

Where

$z_{n} \quad$ : composition of SCN group $\mathrm{n}$, mole percent

$M_{n} \quad$ : molecular weight of SCN group n

A, B : constants determined by the least square fit of experimental data

The generally accepted model of a straight-line relationship is shown Figure 2. Utilizing this model, we can obtain the average absolute deviation between the predicted and experimental studies from twelve data sets is shown figure 3 and 4 . We can observe that the model overpredicts the SCN8 group by more than $25 \%$, whilst SCN 13 group is overpredicted by $30 \%$.

Attempting to compensate for this inaccuracy, Hosein and McCain (2009) argued that this model can only be applied if experimental data up to $\mathrm{C}_{20}+$ are available, making it a minimum seven experimental data to define discontinuities at SCN13 and beyond. Therefore, this scheme is more suited for predicting heptane plus component beyond the SCN 19 group.

\section{Three-Parameter Gamma Distribution Function}

This model is developed by Pearson (1895) and is utilized to characterize molar distribution as a function of molecular weight of pseudo-components as follow

$$
P(x)=\frac{(x-\eta)^{\alpha-1} \exp \left[-\frac{x-\eta}{\beta}\right]}{\beta^{\alpha} \Gamma(\alpha)} \ldots
$$


The parameters represented by Greek Letters $\alpha, \beta, \eta$ are proposed by Whitson (1983) as defining distribution parameters.

This model also works on the same assumption with the exponential distribution model, in which there is a continuous exponential relation between SCN composition and molecular weight, this occurs when the parameter $\alpha$ equals to 1. Al-Meshari and McCain (2007) used the value of $\eta$ as 86.177, equal to the molecular weight of heptane, and applied this modification to predict compositions for twelve data sets.

The Absolute Average Deviation obtained between experimental and numerical data has shown that the SCN8 groups were underpredicted by $25 \%$, whilst the composition of SCN12 and above were overpredicted by $25 \%$, implying that the model does not include discontinuities relationship at SCN8 and SCN13 properly, therefore Hosein and McCain (2009) suggested that extended experimental data up to C14+ are required to make this model a better fit.

\section{Two Coefficient Splitting Scheme}

This method was first derived by Ahmed et al (1985) based on the conclusion that the hydrocarbon systems tend to exhibit a molar distribution that is relative to the average molecular weight in the plus fraction. Ahmed et al (1985) described a marching technique, in which molecular weight data are calculated from experimental PVT data. Ahmed et al (1985) uses four computer-generated plots to receive a generalized coefficient for two segment relationships to calculate mole percent of a certain SCN group.

Ahmed's method was tested by Mayrhoo and Hosein (2014) for twelve samples of gas condensate PVT obtained in Trinidad, and the results yielded better performance compared the previous models, ranging from $8-18 \%$, but the most important flaw in this method is the overprediction of SCN7 group by $23 \%$, which implies that this method cannot be utilized for Trinidad condensates.

\section{Four Coefficient Model}

Mayrhoo and Hosein (2014) attempted to reformulate the flaws in Ahmed et al (1985) scheme by adding two more coefficients and dividing the PVT into four segments, to properly isolate the discontinuities, which results in a modified coefficient based on the pictures below. Mayrhoo and Hosein (2014) divided the segments as

- $\quad$ Segment 1 is from SCN7 to SCN 8 due to the discontinuities whilst segment 2 is from SCN 8 to 12 - $\quad$ Segment 3 is from SCN 12 to SCN 13and segment 4 is beyond SCN 13

The marching technique employed by Ahmed et al (1985) is also used in this scheme, differing in more conservative values of the coefficients used for the condensate characterization. The scheme has been tested against twelve data sets from Trinidad condensates and yields better results, averaging $8 \%$ for all data tests.

The four-coefficient model, however, has never been tested to data sets outside Trinidad condensates, therefore reducing its reliability for field uses around and presenting a lot of complications due to the abundance of coefficients to be accounted for.

\section{PROPOSED NEW MODEL}

Developments in statistics and modeling have encouraged many types of more sophisticated yet simple functions that can be employed to model complicated functions and natural phenomenon. After reviewing all the methods previously developed to characterize heptane plus fractions in gas condensate reservoir, the author decided to employ logarithmic like function to model the distribution of the heptane plus fraction as a function of molecular weight of the mentioned fraction. Experimental results from Hosein and McCain (2009) provided the basis of this research, as the distributions are linear in logarithmic scale, therefore the proposed distribution model that incorporates the exponential distribution is representative to this set. 
The basic equation for the distribution will be defined as

$$
C_{n}=R \ln (x)+S \ldots \text { (3) }
$$

Where $C_{n}$ is defined as percent mole of a certain SCN number, as x is defined as mothe lecular weight of a particular SCN number. The constant A and B will be defined as a fine tuning for each approach to the distribution using the graphical method.

Consider the distribution graphed by Hosein and McCain (2009) obtained a gas condensate well PL6 in Trinidad, using the following data

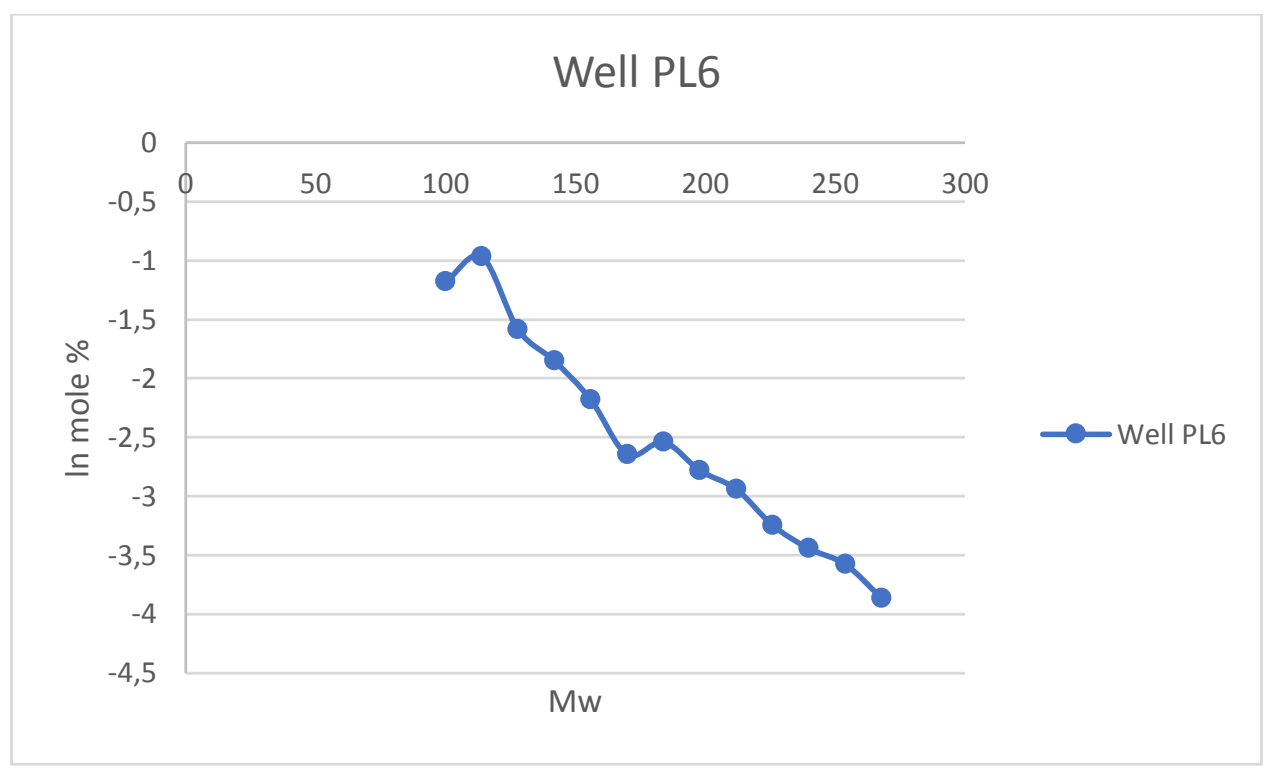

Figure 1- Trends in Heptane Plus Mole Percent to Molecular Weight

In this graph, it is seen that the graph itself can be divided into four sections of the trend line, as what Mayrhoo and Hosein (2014) did in his work of four coefficients model. Mayrhoo and Hosein (2014) however, use the normal graph of percent mole to molecular weight, assuming linearity of all the points plotted. This leads to inaccuracy due to the rounding of the function. Therefore, we propose a new plotting system, using natural logarithmic of percent mole to normal molecular weight. This results in a smoother graph and can be easily inferred as a natural logarithmic function.

We, therefore, break down the graph into four sections, SCN7-8, SCN8-12, SCN12-13, and SCN13-19, as follows 
Steven Chandra/JEEE Vol. 7 No. 1/2018

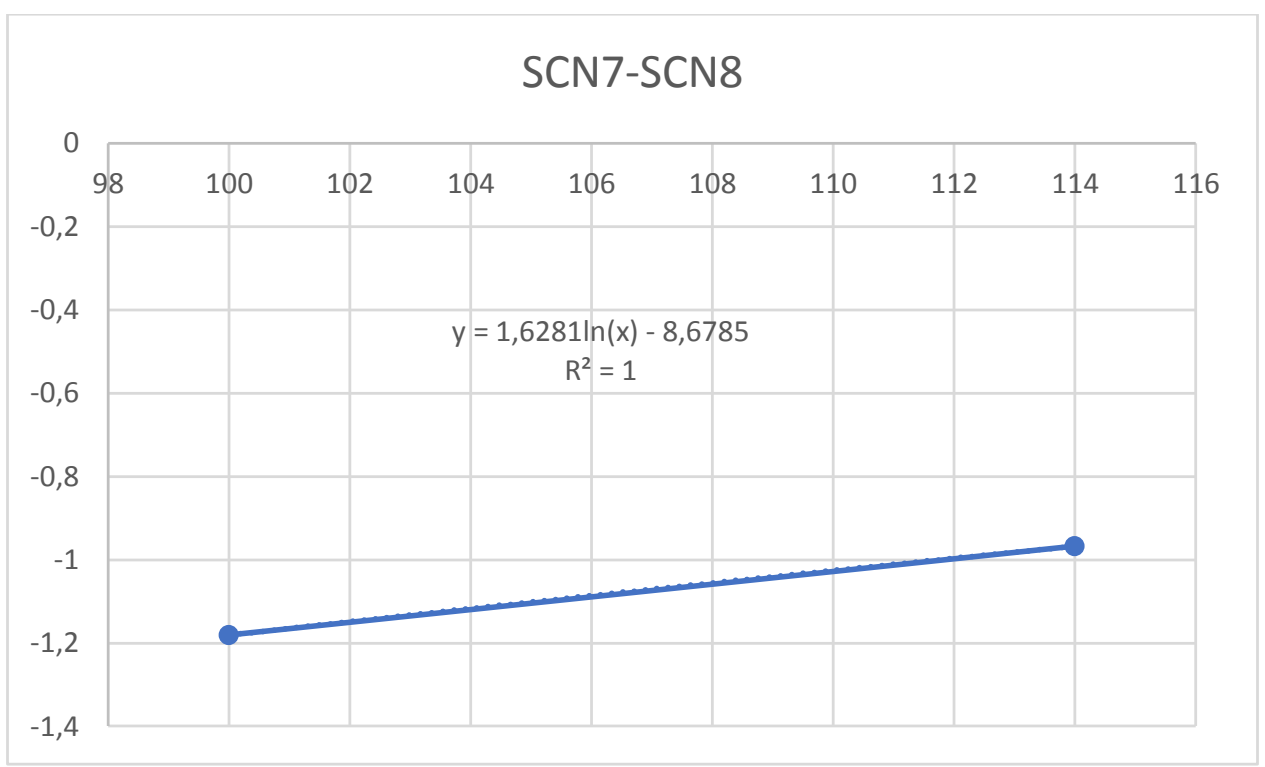

Figure 2-SCN7-SCN8 Trend

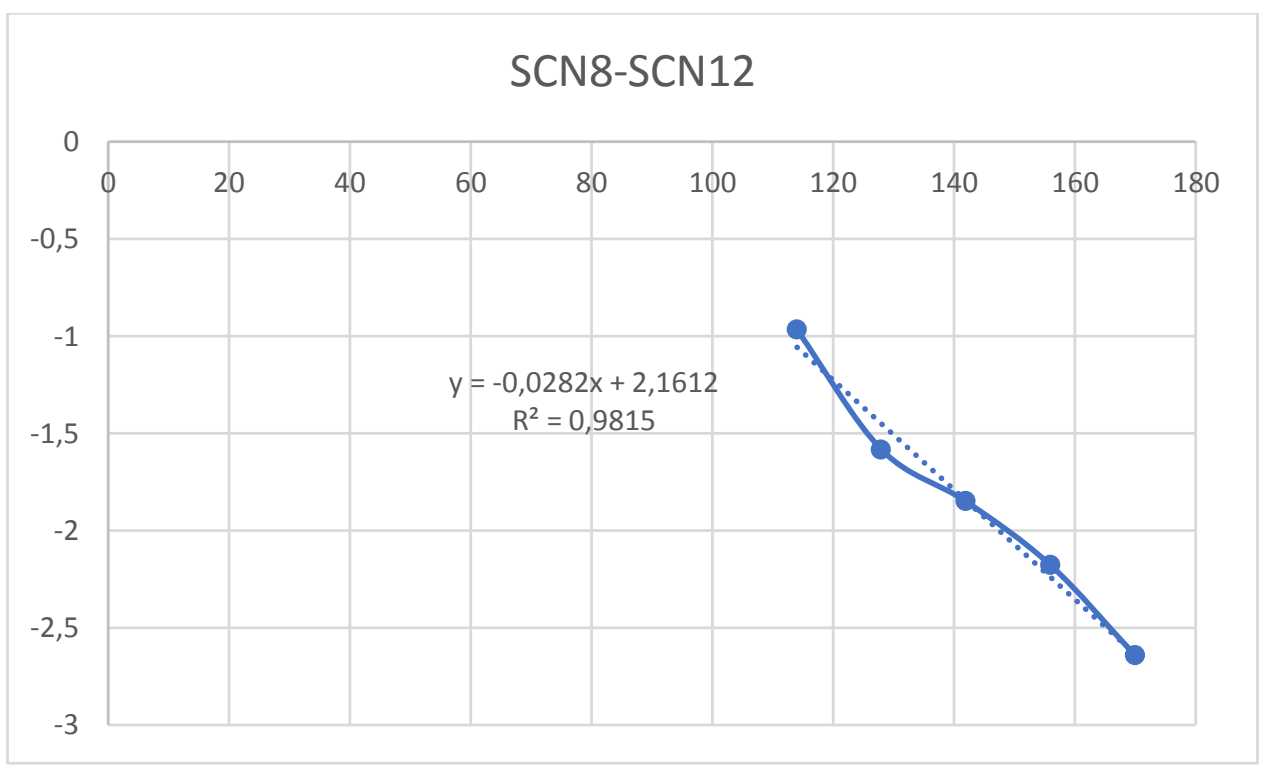

Figure 3- SCN8-SCN12 Trend 


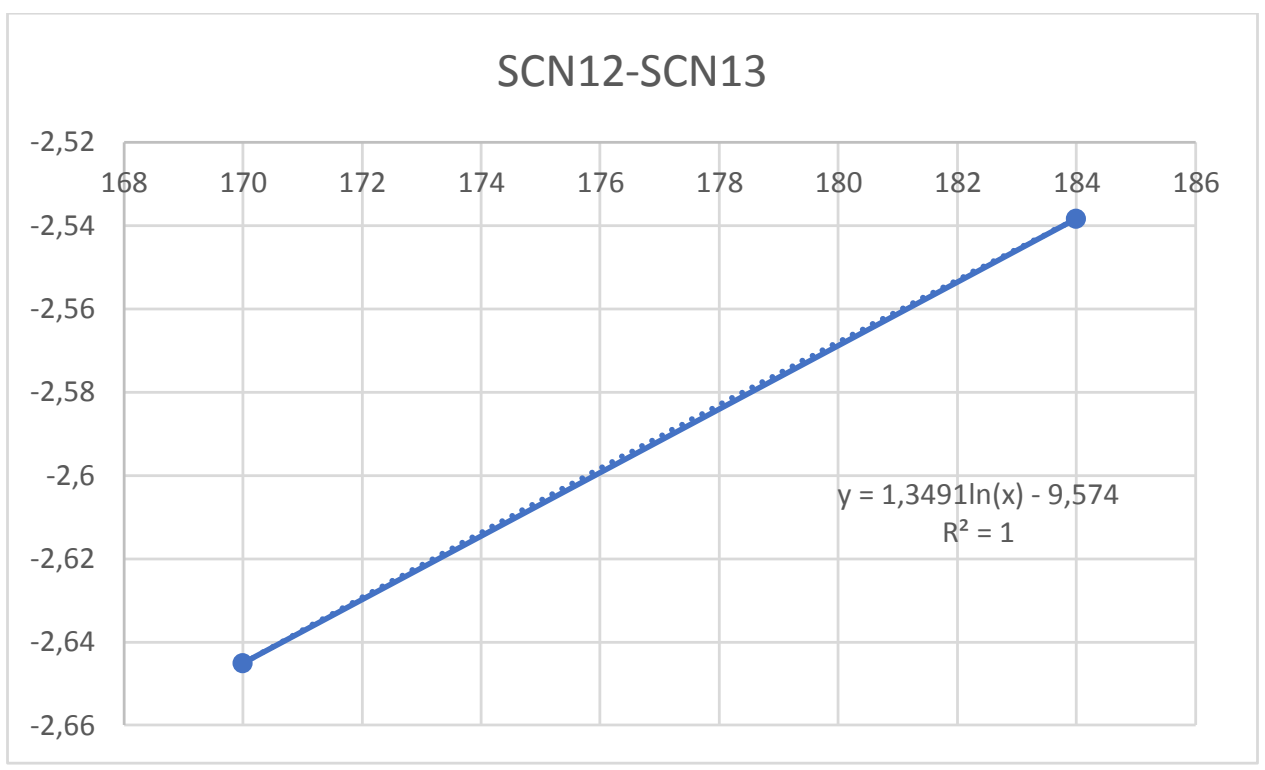

Figure 4-SCN12-SCN13 Trend

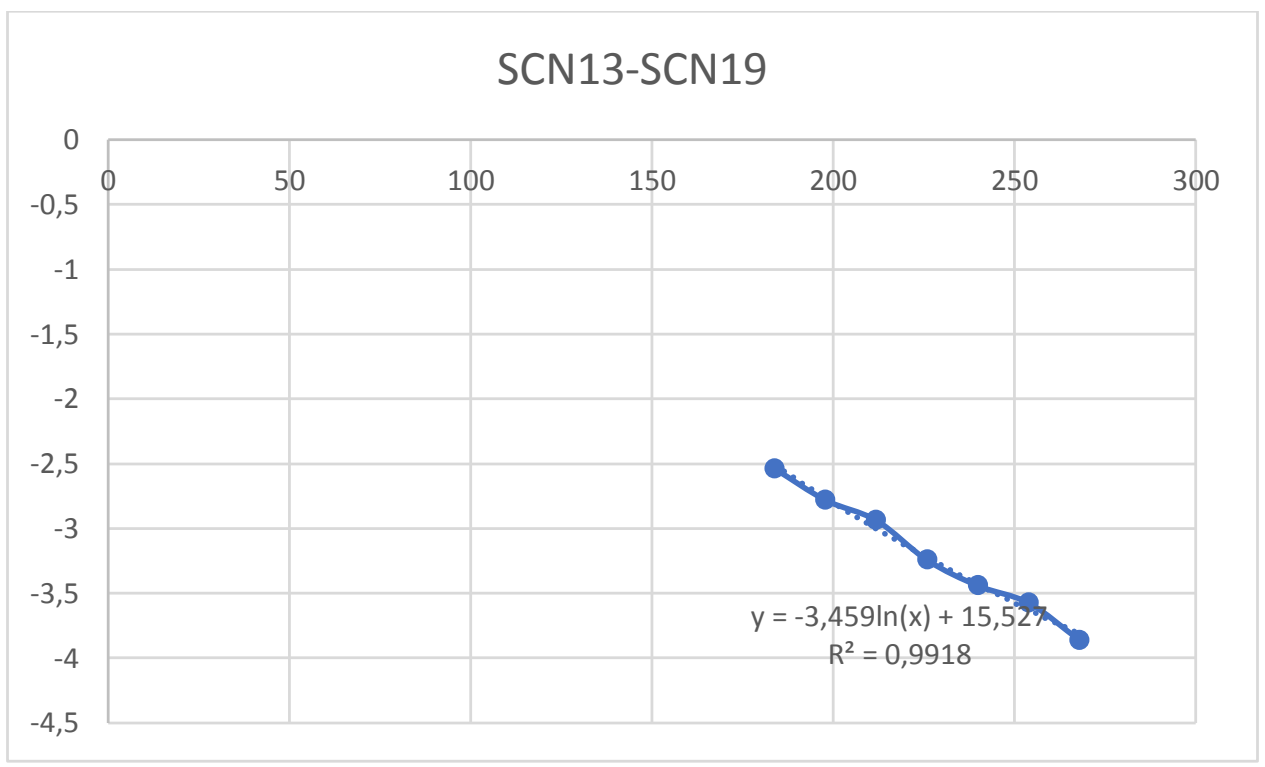

Figure 5-SCN13-SCN19 Trend

The plotted results have shown that converting the values into a natural logarithmic function would lead to better accuracy in modeling discontinuities due to the fact that the discontinuities form a straight line in the natural logarithmic function.

\section{MODEL TESTING}

In this section, several field data from Mayrhoo and Hosein (2014), Hosein and McCain (2009), Whitson and Kuntadi (2005), Katz and Firoozabadi (1978) and Hoffman et al (1953) will be used as a baseline study to determine the proper coefficients for each part of the graph as mentioned above. The values will then be averaged as a final model that will be tested against 2 sets of field data to determine its accuracy. 
Table 1-List of PVT Data Used for Model Building

\begin{tabular}{|c|c|c|c|c|c|c|c|c|}
\hline \multirow[t]{2}{*}{ Sample } & \multicolumn{2}{|l|}{ SCN7-SCN8 } & \multicolumn{2}{|c|}{ SCN8-SCN12 } & \multicolumn{2}{|c|}{ SCN12-SCN13 } & \multicolumn{2}{|c|}{ SCN13-SCN19 } \\
\hline & $\mathbf{R}$ & $\mathbf{S}$ & $\mathbf{R}$ & $\mathbf{S}$ & $\mathbf{R}$ & $\mathbf{S}$ & $\mathbf{R}$ & $\mathbf{S}$ \\
\hline PL1 & 1.673 & -8.61 & -0.028 & 2 & 1.12 & -9.51 & -3.48 & 15.21 \\
\hline PL2 & 1.629 & -8.69 & -0.0271 & 2.21 & 1.39 & -9.49 & -3.476 & 15.409 \\
\hline PL3 & 1.71 & $-\overline{8.602}$ & -0.0276 & 2.18 & 1.32 & -9.58 & -3.462 & 15.388 \\
\hline PL4 & 1.65 & -8.58 & -0.0289 & 2.11 & 1.22 & -9.43 & -3.501 & 15.89 \\
\hline PL5 & 1.633 & -8.54 & -0.0283 & 2.19 & 1.29 & -9.566 & -3.402 & 15.602 \\
\hline PL6 & 1.62 & -8.67 & -0.0282 & 2.16 & 1.349 & -9.574 & -3.459 & 15.527 \\
\hline CL1 & 1.591 & -8.51 & -0.029 & 2.08 & 1.372 & -9.601 & -3.644 & 15.781 \\
\hline CL2 & 1.6 & $-\overline{8.533}$ & $\begin{array}{l}- \\
0.02871\end{array}$ & 2.06 & 1.389 & -9.544 & -3.604 & 15.293 \\
\hline CL3 & 1.613 & $-\overline{8.601}$ & -0.0288 & 2.17 & 1.36 & -9.53 & -3.595 & 15.901 \\
\hline CL4 & 1.588 & -8.77 & -0.0275 & 2.11 & 1.4 & -9.501 & -3.622 & 15.655 \\
\hline CL5 & 1.593 & -8.69 & -0.0284 & 2.19 & 1.43 & -9.522 & -3.659 & 16.011 \\
\hline CL6 & 1.632 & -8.56 & -0.0281 & 2.08 & 1.23 & -9.573 & -3.612 & 15.832 \\
\hline $\mathrm{K} 1 / \mathrm{K} 4$ & 1.688 & -8.7 & -0.029 & 2.21 & 1.28 & -9.62 & -3.78 & 15.21 \\
\hline Ghawar & 1.621 & -8.89 & -0.0294 & 2.2 & 1.25 & -9.65 & -3.733 & 15.292 \\
\hline $\begin{array}{l}\text { Al-Meshari } \\
1\end{array}$ & 1.709 & -8.65 & -0.0279 & 2.11 & 1.301 & -9.42 & -3.56 & 15.398 \\
\hline $\begin{array}{l}\text { Al-Meshari } \\
2\end{array}$ & 1.7 & -8.59 & -0.0276 & 2.18 & 1.34 & -9.48 & -3.819 & 15.481 \\
\hline Pedersen 1 & 1.682 & -8.73 & -0.0284 & 2.16 & 1.39 & -9.61 & -3.321 & 15.982 \\
\hline Pedersen II & 1.675 & $\begin{array}{l}- \\
8.712\end{array}$ & -0.0281 & 2.13 & 1.376 & -9.64 & -3.49 & 16.023 \\
\hline Average & 1.64483333 & $\begin{array}{l}- \\
8.646\end{array}$ & $\overline{0} .02828$ & 2.140556 & 1.322611 & 9.54672 & $-\overline{3.56772}$ & 15.60472 \\
\hline
\end{tabular}

After studying several data sets, the values of every A and B coefficients for every splitting of the SCN numbers are then averaged, resulting in values that can be used to model the Heptane Plus Characterization. The model is then tested using two sets of field data extracted from Ahmed et al (1985) which uses two data sets from North Sea Gas Condensates and Bazanan Gas Condensate reservoir.

Results for the model testing is shown below, in which the predicted model gives promising results for modeling heptane plus fraction up to SCN 20+. The differences from the experimental procedures can be minimalized should there be more representative data to further enhance the model, as condensate compositions vary with regional deposition and properties of the PVT itself. The difference between the experimentally derived composition and the calculated is less than $3 \%$, making it suitable for this model to be used as a tool for heptane plus characterization in condensate reservoirs. 
Table 2-Results of Model Testing

\begin{tabular}{llllllll}
\hline $\begin{array}{l}\text { SCN } \\
\text { Group }\end{array}$ & $\begin{array}{l}\text { North } \\
\text { Sea }\end{array}$ & Bazanan & $\begin{array}{l}\text { Calc. } \\
\text { Sea }\end{array}$ & $\begin{array}{l}\text { North } \\
\text { Mole\% }\end{array}$ & & $\begin{array}{l}\text { Calc. } \\
\text { Bazanan }\end{array}$ & \multicolumn{2}{l}{ Difference } & (\%) \\
\hline $\mathbf{7}$ & 1.21 & 0.75 & 1.193 & 0.744 & 1.40 & 0.80 \\
\hline $\mathbf{8}$ & 1.1 & 0.76 & 1.079 & 0.771 & 1.91 & 1.45 \\
\hline $\mathbf{9}$ & 0.86 & 0.49 & 0.859 & 0.482 & 0.12 & 1.63 \\
\hline $\mathbf{1 0}$ & 0.68 & 0.31 & 0.682 & 0.313 & 0.29 & 0.97 \\
\hline $\mathbf{1 1}$ & 0.568 & 0.22 & 0.571 & 0.2172 & 0.53 & 1.27 \\
\hline $\mathbf{1 2}$ & 0.478 & 0.15 & 0.48 & 0.146 & 0.42 & 2.67 \\
\hline $\mathbf{1 3}$ & 0.407 & 0.12 & 0.405 & 0.118 & 0.49 & 1.67 \\
\hline $\mathbf{1 4}$ & 0.35 & 0.09 & 0.346 & 0.087 & 1.14 & 3.33 \\
\hline $\mathbf{1 5}$ & 0.302 & 0.07 & 0.309 & 0.0723 & 2.32 & 3.29 \\
\hline $\mathbf{1 6}$ & 0.262 & 0.05 & 0.268 & 0.0533 & 2.29 & 6.60 \\
\hline $\mathbf{1 7}$ & 0.228 & 0.04 & 0.22 & 0.0391 & 3.51 & 2.25 \\
\hline $\mathbf{1 8}$ & 0.199 & 0.03 & 0.204 & 0.0295 & 2.51 & 1.67 \\
\hline $\mathbf{1 9}$ & 0.174 & 0.02 & 0.177 & 0.0194 & 1.72 & 3.00 \\
\hline $\mathbf{2 0}$ & 0.153 & 0.02 & 0.156 & 0.0204 & 1.96 & 2.00 \\
\hline Average Differences & & & & 1.47 & 2.33 \\
\hline
\end{tabular}

\section{CONCLUSION}

A new model has been derived based on four coefficient model and marching technique that capable of modeling heptane plus characterization with simple calculations. Model testing using field data has been successfully conducted to present low level of difference from experimental data.

\section{NOMENCLATURE}

AAD : Absolute Average Deviation

A,B : Constants in Pedersen Model

Cn : Mole Percent of an SCN Number in Proposed Model

MW : Molecular Weight

P : Pressure, psi

PVT : Pressure Volume and Temperature

R,S : Coefficients in Proposed Model

SCN : Single Carbon Number

$\mathrm{Z}_{\mathrm{n}} \quad$ : Mole Percent of an SCN fraction in a Hydrocarbon Mixture

\section{Greek Letters}

A, $\beta, \eta \quad$ : Coefficients of The Gamma Distribution Function

$\Gamma \quad$ : Gamma Function 


\section{REFERENCES}

Spivey, J. P., \& McCain, W. D. (2013, September). Estimating Reservoir Composition for Gas Condensates and Volatile Oils from Field Data. In SPE Annual Technical Conference and Exhibition. Society of Petroleum Engineers.

Imo-Jack, O. O., \& Uche, I. N. (2012, January). Splitting the Heptanes-Plus fraction of Condensate and Volatile systems: Application of the Gamma Distribution Model. In Nigeria Annual International Conference and Exhibition. Society of Petroleum Engineers

Danesh, A. (1998). PVT and phase behaviour of petroleum reservoir fluids (Vol. 47). Elsevier.

Ahmed, T. H. (1989). Hydrocarbon phase behavior (Vol. 7). Gulf Pub Co.

Mayrhoo, R., \& Hosein, R. (2014, June). A Model for Extending the Heptanes plus Fraction for Trinidad Gas Condensates. In SPE Energy Resources Conference. Society of Petroleum Engineers.

Whitson, C. H., \& Brulé, M. R. (2000). Phase Behavior, The Society of Petroleum Engineers. Inc., Richardson, TX.

Pederson, K. S., Thomason, P., \& Fredenslund, A. (1985). Thermodynamics of Petroleum. Mixtures Containing Heavy Hydrocarbons. Ind. Eng. Chem. Des. Dev, 24(4), 948-954.

Pearson, K. (1895). Contributions to the mathematical theory of evolution. II. Skew variation in homogeneous material. Philosophical transactions of the Royal Society of London, 186(Part I), 343424.

Al-Meshari, A. A., \& McCain Jr, W. (2007, January). Validation of Splitting the Hydrocarbon plus Fraction First step in tuning Equation-of-State. In SPE Middle East Oil and Gas Show and Conference. Society of Petroleum Engineers.

Hosein, R., \& McCain, W. D. (2009). Extended analysis for gas condensate systems. SPE Reservoir Evaluation \& Engineering, 12(01), 159-166.

Whitson, C. H. (1983). Characterizing hydrocarbon plus fractions. Society of Petroleum Engineers Journal, 23(04), 683-694.

Ahmed, T. H., Cady, G. V., \& Story, A. L. (1985, January). A generalized correlation for characterizing the hydrocarbon heavy fractions. In SPE Annual Technical Conference and Exhibition. Society of Petroleum Engineers.

Whitson, C. H., \& Kuntadi, A. (2005, January). Khuff gas condensate development. In International Petroleum Technology Conference. International Petroleum Technology Conference.

Katz, D. L., \& Firoozabadi, A. (1978). Predicting phase behavior of condensate/crude-oil systems using methane interaction coefficients. Journal of Petroleum Technology, 30(11), 1-649.

Hoffman, A. E., Crump, J. S., \& Hocott, C. R. (1953). Equilibrium constants for a gas-condensate system. Journal of Petroleum Technology, 5(01), 1-10. 


\section{Appendix A}

Table 3-PVT Composition Used for Model Building

\begin{tabular}{cccccccccc}
\hline SCN & & & \multicolumn{7}{c}{ \%Mole } \\
\hline Group & PL1 & PL2 & PL3 & PL4 & PL5 & PL6 & CL1 & CL2 & CL3 \\
\hline $\mathbf{7}$ & 0.561 & 0.458 & 0.508 & 0.346 & 0.368 & 0.307 & 0.588 & 0.353 & 0.39 \\
\hline $\mathbf{8}$ & 0.789 & 0.583 & 0.652 & 0.444 & 0.471 & 0.38 & 0.729 & 0.457 & 0.486 \\
\hline $\mathbf{9}$ & 0.491 & 0.319 & 0.353 & 0.308 & 0.297 & 0.205 & 0.491 & 0.304 & 0.322 \\
\hline $\mathbf{1 0}$ & 0.354 & 0.245 & 0.286 & 0.231 & 0.208 & 0.157 & 0.327 & 0.222 & 0.225 \\
\hline $\mathbf{1 1}$ & 0.267 & 0.196 & 0.194 & 0.165 & 0.141 & 0.133 & 0.246 & 0.162 & 0.171 \\
\hline $\mathbf{1 2}$ & 0.176 & 0.127 & 0.134 & 0.108 & 0.089 & 0.071 & 0.156 & 0.118 & 0.115 \\
\hline $\mathbf{1 3}$ & 0.197 & 0.148 & 0.146 & 0.122 & 0.101 & 0.079 & 0.169 & 0.129 & 0.123 \\
\hline $\mathbf{1 4}$ & 0.17 & 0.105 & 0.121 & 0.095 & 0.079 & 0.062 & 0.151 & 0.101 & 0.106 \\
\hline $\mathbf{1 5}$ & 0.144 & 0.093 & 0.103 & 0.084 & 0.069 & 0.053 & 0.121 & 0.088 & 0.093 \\
\hline $\mathbf{1 6}$ & 0.119 & 0.074 & 0.077 & 0.068 & 0.052 & 0.039 & 0.098 & 0.068 & 0.069 \\
\hline $\mathbf{1 7}$ & 0.104 & 0.066 & 0.065 & 0.059 & 0.045 & 0.032 & 0.085 & 0.059 & 0.059 \\
\hline $\mathbf{1 8}$ & 0.099 & 0.054 & 0.052 & 0.049 & 0.037 & 0.028 & 0.076 & 0.052 & 0.054 \\
\hline $\mathbf{1 9}$ & 0.08 & 0.045 & 0.041 & 0.04 & 0.031 & 0.021 & 0.064 & 0.044 & 0.043 \\
\hline $\mathbf{2 0}+$ & 0.373 & 0.24 & 0.187 & 0.149 & 0.134 & 0.069 & 0.344 & 0.232 & 0.222 \\
\hline
\end{tabular}

\begin{tabular}{cccccccccc}
\hline SCN & & & & & \multicolumn{3}{c}{ \%ole } & & \\
Group & CL4 & CL5 & CL6 & K1/K4 & Ghawar & $\begin{array}{c}\text { Al-Meshari } \\
\mathbf{1}\end{array}$ & $\begin{array}{c}\text { Al-Meshari } \\
\mathbf{2}\end{array}$ & $\begin{array}{c}\text { Pedersen } \\
\text { I }\end{array}$ & $\begin{array}{c}\text { Pedersen } \\
\text { II }\end{array}$ \\
\hline $\mathbf{7}$ & 0.523 & 0.414 & 0.294 & 0.486 & 0.532 & 1.6 & 1.5 & 4.39 & 3.33 \\
\hline $\mathbf{8}$ & 0.633 & 0.504 & 0.367 & 0.361 & 0.41 & 1.31 & 1.65 & 4.71 & 4.06 \\
\hline $\mathbf{9}$ & 0.352 & 0.31 & 0.234 & 0.266 & 0.317 & 1.31 & 1.36 & 3.21 & 2.76 \\
\hline $\mathbf{1 0}$ & 0.238 & 0.215 & 0.159 & 0.201 & 0.254 & 1.12 & 1.16 & 1.76 & 1.33 \\
\hline $\mathbf{1 1}$ & 0.196 & 0.162 & 0.112 & 0.153 & 0.206 & 0.86 & 0.91 & 1.72 & 1.79 \\
\hline $\mathbf{1 2}$ & 0.11 & 0.1 & 0.07 & 0.116 & 0.169 & 0.7 & 0.75 & 1.74 & 1.7 \\
\hline $\mathbf{1 3}$ & 0.123 & 0.112 & 0.08 & 0.089 & 0.14 & 0.63 & 0.7 & 1.74 & 1.81 \\
\hline $\mathbf{1 4}$ & 0.099 & 0.09 & 0.056 & 0.068 & 0.117 & 0.57 & 0.61 & 1.35 & 1.46 \\
\hline $\mathbf{1 5}$ & 0.086 & 0.076 & 0.046 & 0.052 & 0.097 & 0.51 & 0.59 & 1.34 & 1.49 \\
\hline $\mathbf{1 6}$ & 0.066 & 0.064 & 0.039 & 0.04 & 0.081 & 0.43 & 0.48 & 1.06 & 1.08 \\
\hline $\mathbf{1 7}$ & 0.055 & 0.056 & 0.032 & & & 0.38 & 0.43 & 1.02 & 1.13 \\
\hline $\mathbf{1 8}$ & 0.047 & 0.047 & 0.027 & 0.073 & 0.171 & 0.35 & 0.41 & 1 & 0.99 \\
\hline $\mathbf{1 9}$ & 0.039 & 0.039 & 0.019 & & & 0.32 & 0.37 & 0.9 & 0.88 \\
\hline $\mathbf{2 0}+$ & 0.184 & 0.218 & 0.057 & 0.063 & 0.186 & 4.71 & 4.74 & 0.918 & 7.64 \\
\hline
\end{tabular}

